\title{
Effect of flow velocity on the process of air-steam condensation in a vertical tube condenser
}

\author{
Jan Havlík ${ }^{1, *}$, Tomáš Dlouhý ${ }^{1}$ \\ ${ }^{1}$ Czech Technical University in Prague, Faculty of Mechanical Engineering, Department of Energy Engineering, Technicka 4, \\ 16607 Prague 6, Czech Republic
}

\begin{abstract}
This article describes the influence of flow velocity on the condensation process in a vertical tube. For the case of condensation in a vertical tube condenser, both the pure steam condensation process and the air-steam mixture condensation process were theoretically and experimentally analyzed. The influence of steam flow velocity on the value of the heat transfer coefficient during the condensation process was evaluated. For the condensation of pure steam, the influence of flow velocity on the value of the heat transfer coefficient begins to be seen at higher speeds, conversely, this effect is negligible at low values of steam velocity. On the other hand, for the air-steam mixture condensation, the influence of flow velocity must always be taken into account. The flow velocity affects the water vapor diffusion process through non-condensing air. The presence of air significantly reduces the value of the heat transfer coefficient. This drop in the heat transfer coefficient is significant at low velocities; on the contrary, the decrease is relatively small at high values of the velocity.
\end{abstract}

\section{Introduction}

Condensers are used in a variety of chemical, petroleum, processing and power facilities for distillation, refrigeration and power generation. Most condensers used in the chemical process industries are water cooled shell-and-tube exchangers and air cooled tube or platen exchangers. Shell-and-tube condensers, which are used for the condensation of process vapors, are classified according to orientation (horizontal and vertical) and placement of condensing vapor (shell-side and tube-side) [1]. For industrial waste vapor, which may contain small solid particles (e.g. vapors from drying processes and other material processes [2]), a vertical tube-side configuration is used. These solid particles, which can stick to the tube wall, are spontaneously carried away from the tubes by the condensate blowing out. This design is very flexible and is suitable where a particularly low pressure drop is specified for the condensing fluid.

A vertical tube-side condenser consists of a shell with fixed tubesheets. The lower head is over-sized to accumulate the condensate and must be equipped with a vent for removing non-condensable gases. The condensate flows down the tubes in the form of an annular film of liquid, thereby maintaining good contact with both the cooling surface and the remaining vapor. The disadvantages are that the coolant, which is often more prone to fouling, is on the shell side, and the use of finned tubes is precluded.

Calculation of the overall heat transfer coefficient (HTC) necessary for the design of the condenser heat transfer area is well described in the literature, however for limited operating conditions only. The Nusselt condensation model commonly recommended for the calculation of condensing side HTC is derived for conditions which need not be satisfied in real operation [3], [4]. In many process industry applications, the vapor to be condensed is multicomponent in nature. Such cases include those where the single condensing vapor is mixed with a non-condensable gas. The presence of such gases can have profound effects on condensation greatly reducing the effective HTC.

\section{Theory of condensation in a vertical tube}

The basic heat-transfer model for film condensation was first derived by Nusselt to describe how a purecomponent saturated vapor condenses on a vertical wall, forming a thin film of condensate that flows downward due to gravity [3], [4]. Then the following equation for the calculation of the HTC $h_{c}$ was introduced

$$
h_{c}=\frac{2 \sqrt{2}}{3}\left[\frac{\rho_{L} g\left(\rho_{L}-\rho_{p}\right) h_{f g}^{\prime} k_{L}^{3}}{\mu_{L} \Delta T_{s a t} L}\right]^{1 / 4}
$$

where $\rho_{L}$ is the density of the condensate, $\rho_{p}$ is the density of the water vapor, $h_{f g}^{\prime}$ is the latent heat of condensation, $k_{L}$ is the thermal conductivity of the condensate, $\mu_{L}$ is the dynamic viscosity of the condensate, $\Delta T_{\text {sat }}$ is the difference between the saturation

Corresponding author: jan.havlik@fs.cvut.cz 
temperature and the wall temperature, and $L$ is the wall length.

The model was derived with the assumptions of a laminar flow in the condensate film, a linear temperature profile across the condensate film (this assumption is reasonable for a very thin film), a negligible shear stress at the vapor-liquid interface and a low fluid velocity in the film. The operating conditions of condensers may be different from the assumptions adopted in the basic Nusselt theory. Deviations in the operation of real devices may be caused for example by the influence of condensing vapor velocity or the presence of noncondensable air in the vapor on the condensation process.

\subsection{Effect of flow velocity}

During condensation inside vertical tubes, steam works on the film surface by shear force. When the steam flows downward, film flows accelerate and the HTC increases slightly. On the contrary, moving upward slows down the film flow [4], [5].

The velocity in the liquid film for gravity controlled condensation (the basic Nusselt model) can be written as

$$
u(y)=\frac{g\left(\rho_{L}-\rho_{v}\right)}{\mu_{L}}\left[y \delta-\frac{1}{2} y^{2}\right]
$$

where $u$ is the liquid velocity within the film at a distance $y$ from the wall. At higher steam velocities, the interfacial shear becomes significant compared to the gravitational force on the liquid phase. For a partial velocity of the film given by shear stress, we can write

$$
u(y)=\frac{\tau_{g}}{\mu_{L}} y
$$

where $\tau_{g}$ is the interfacial shear stress. The resulting equation for the velocity combines Eq. (2) and Eq. (3) in the form

$$
u(y)=\frac{g\left(\rho_{L}-\rho_{v}\right)}{\mu_{L}}\left[y \delta-\frac{1}{2} y^{2}\right]+\frac{\tau_{g}}{\mu_{L}} y
$$

$\tau_{g}$ can be determined according to the following relation, where $u_{g}$ is the velocity of the flowing gas and $f$ is the coefficient of friction losses, its determination is described e.g. in [1], [2], [5].

$$
\tau_{g}=\frac{1}{2} \rho u_{g}^{2} f
$$

A change in the velocity profile of the condensate film influences the calculation of the condensation HTC. The calculation process is described in detail in the works of Kageyama [7], Rohsenow [8] and Blangetti [9].

\subsection{Condensation of steam mixture}

The problem of steam mixture condensation is described in detail in [9]. If steam condenses in a mixture with inert gases, there is a difference in the concentrations of the steam in the bulk gas mixture and at the condensation phase interface. Steam concentrations decrease along the length of the tube equally with corresponding steam partial pressures $p_{\infty}$ resp. $p_{i}$ and temperatures $T_{\infty}$ resp. $T_{i}$ (see Figure 1). The molecules of steam diffuse through an inert gas towards the vapor-liquid interface and mass transfer occurs [1], [4]. On the contrary in the case of pure steam condensation, the temperatures $T_{\infty}$ and $T_{i}$ are identical and constant during the process [10].

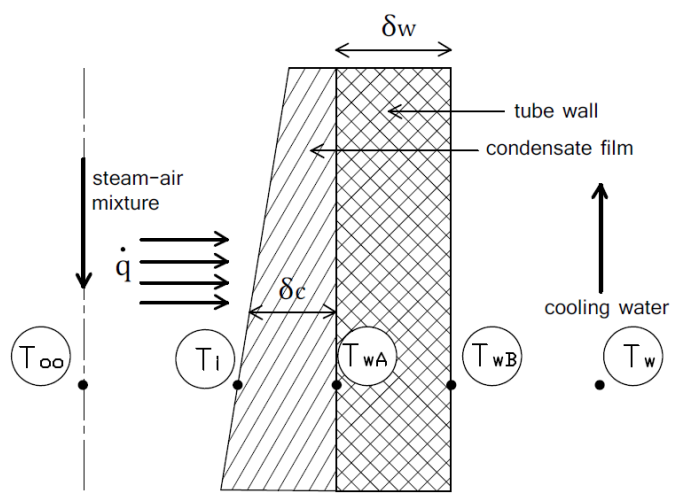

Fig. 1. Scheme of the condensation process [10]

To determine the HTC value, it is necessary to calculate the condensation temperature at the phase interface $T_{i}$ taking into account the mass transfer generated by the different partial pressures at the interface between the gas and the liquid phases $p_{i}$ and the bulk gas mixture $p_{\infty}$ [1], [4], [5]. In accordance with the analogy between the mass transfer and the heat transfer, the condensation HTC is evaluated according to the Nusselt model combined with the application of the suitable criterion equation for the mass transfer [10].

Condensing molar flux $\dot{n}_{v}$ describes the balance of the process

$$
\dot{n}_{v}=\beta C_{T} \ln \left[\frac{1-\bar{y}_{v, \infty}}{1-\bar{y}_{v, i}}\right]
$$

where $\beta$ is the mass transfer coefficient, $C_{T}$ is the total molar concentration, $\bar{y}_{v, \infty}$ is the steam mole fraction in the bulk gas mixture, respective at the liquid-vapor interface $\bar{y}_{v, i}$. The mass transfer coefficient $\beta$ is determined according to the suitable criterial equation analogically with the heat transfer. The partial pressure $p_{v, i}$ at the liquid-vapor interface is given as

$$
p_{v, i}=\bar{y}_{v, i} p
$$

and the temperature at the liquid-vapor interface $T_{i}$ as

$$
T_{i}=T_{s a t}\left(p_{v, i}\right)
$$

\section{Experiment}

In order to verify of the described theory experiments were carried out on a vertical shell-and-tube heat exchanger in which the condensing water vapor flows downwards inside vertical tubes and the cooling water flows in a counter current in the outer shell. 


\subsection{Experimental set-up}

The condenser is shown in Fig. 1. The tube bundle is formed by 49 tubes $865 \mathrm{~mm}$ in length, $28 \mathrm{~mm}$ in external diameter and $24 \mathrm{~mm}$ in internal diameter. The tubes are arranged in staggered arrays with a triangular tube pitch of $35 \mathrm{~mm}$. The cross-section of the shell is rectangular in shape, $223 \mathrm{~mm}$ by $270 \mathrm{~mm}$ in size. Seven segmental baffles $(223 \times 230 \mathrm{~mm})$ are used in the shell section. The tubes are made from stainless steel 1.4301 (AISI 304).
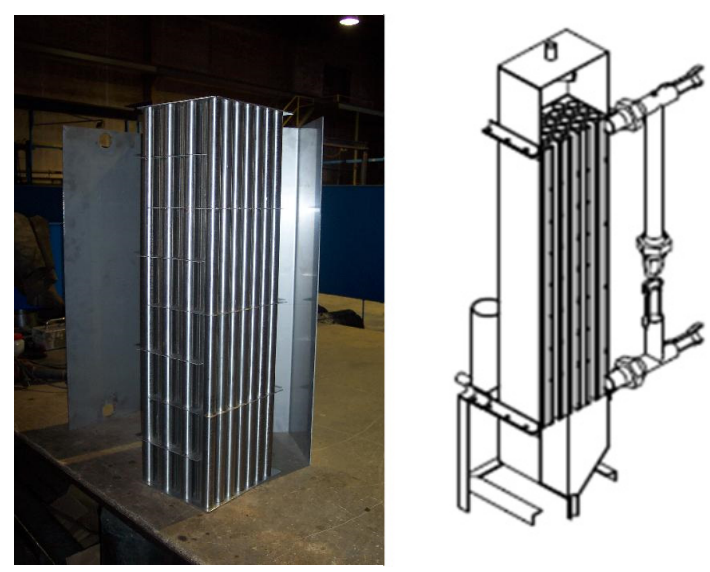

Fig. 1. Vertical tube condenser

The testing loop is shown in Fig. 2. Steam is produced in a steam generator. Before the steam enters the vertical tube condenser, its parameters are reduced to the required values. Hot water recirculation makes it possible to set the cooling water temperature and the cooling water flow rate in the condenser to the required values.

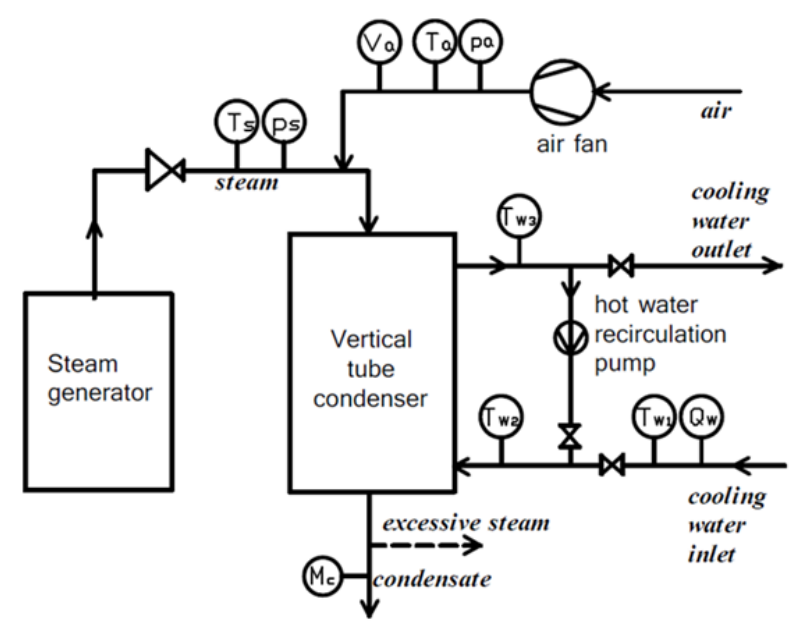

Fig. 2. Scheme of the testing loop

The measured parameters are the inlet cooling water temperature $T_{w 1}$, the temperature of the water after recirculation $T_{w 2}$, the outlet cooling water temperature $T_{w 3}$, the cooling water flow rate $Q_{w}$, the inlet steam pressure $p_{s}$, the inlet steam temperature $T_{S}$ and the amount of steam condensate $M_{c}$.

\subsection{Determination of the condensation HTC}

Calculation of the HTC is based on the heat balance of the condenser [1]. The total heat power $Q$ is given by the equation

$$
Q=M_{w} \cdot c_{w} \cdot\left(T_{w, o u t}-\mathrm{T}_{w, \text { in }}\right),
$$

where $M_{w}$ is the cooling water flow, $c_{w}$ is the specific heat capacity of water, $T_{w, o u t}$ is the outlet cooling water temperature, and $T_{w, i n}$ is the inlet cooling water temperature. The overall HTC $U$ is given by the equation

$$
U=\frac{Q}{A \cdot \Delta T_{\log }}
$$

where $A$ is the heat transfer surface and $\Delta T_{\log }$ is the logarithmic mean temperature difference. It is possible to calculate the tube-side HTC (vapor condensation) $h_{c}$ from the term for determining the overall HTC

$$
U=\frac{1 / D_{o}}{\frac{1}{d_{i} \cdot h_{c}}+\frac{1}{2 k} \ln \left(\frac{D_{o}}{d_{i}}\right)+\frac{1}{D_{o} \cdot h_{w}}}
$$

where $d_{i}$ is the inside diameter of the tubes, $k$ is the thermal conductivity of the tubes, $h_{w}$ is the tube-side HTC (cooling water side), and $D_{o}$ is the outside diameter of the tubes.

The value of the cooling water HTC $h_{w}$ was experimentally evaluated [11], [12]. The criterion equation for calculation of the HTC in the cooling water side of the experimental condenser was determined by the Wilson plot method [13], [14]. The experimentally derived equation has the following form [11] as

$$
N u=0.270 \operatorname{Re}^{0.56} \operatorname{Pr}^{0.33}\left(\frac{\mu}{\mu_{s}}\right)^{0.14}
$$

afterwards $h_{w}$ is given by the equation

$$
h_{w}=\frac{N u \cdot k_{w}}{D}
$$

The process for the experimental determination of the heat transfer coefficient and the proposal of the criterion equation of shell-and-tube condensers using the Wilson plot method is described in detail in [11].

\section{Results}

Experiments were carried for the case of pure steam condensation and the case of air-steam mixture condensation. During the condensation process the gas velocity decreases together with a decrease of the volume flow of the condensing gas. Therefore, the range of small values of the velocity was analyzed.

\subsection{Pure steam}

After determination of $h_{w}$ from Eq. (13), the value of $h_{c}$ for various gas velocities is provided from Eq. (11). It is 
necessary to maintain constant conditions on the cooling water side. The results for 3 different levels of cooling conditions are shown in Fig. 4.

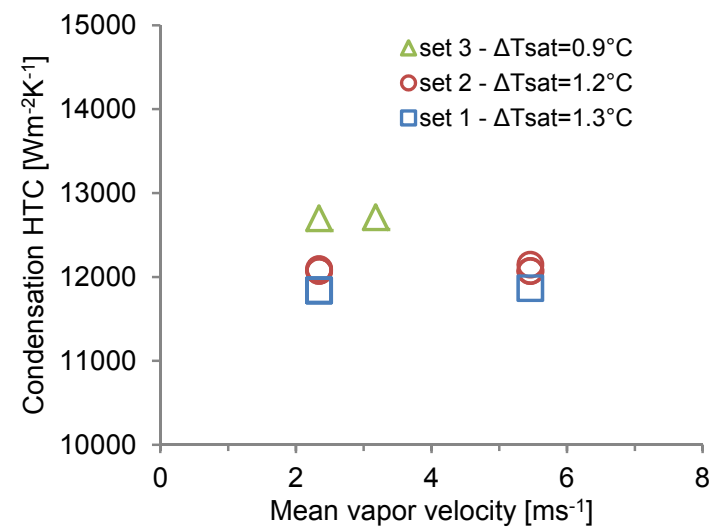

Fig. 4. Experimentally given dependencies of the HTC on pure steam velocity

The values of condensation HTC reach similar values for various velocities in all 3 analyzed cases. The effect of steam velocity is negligible at low velocity values. Condensation HTC is only sensitive to the difference $\Delta T_{\text {sat }}$ (Eq. 1) between the saturation temperature $T_{i}$ and the wall temperature $T_{w A}$ (see Fig. 1).

Based on the Blangetti model, the dependence of the HTC on the condensing steam velocity was created. In Fig. 5, an increase of the condensation HTC is shown to be caused by an increase of the steam velocity.

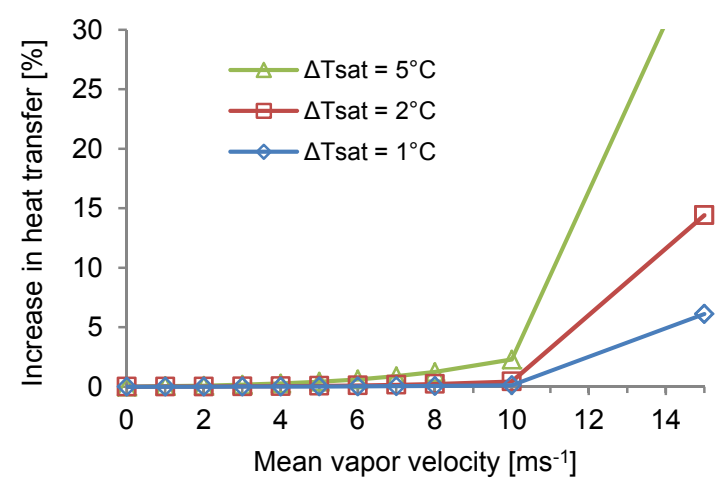

Fig. 5. Theoretically calculated effect of pure steam velocity on the condensation HTC

It can be seen that the influence of velocity is also dependent on the difference between the temperature of the condensation on the film surface and the wall temperature. In general, the rate for a temperature difference of less than $5{ }^{\circ} \mathrm{C}$ begins to influence the magnitude of the heat transfer coefficient at steam velocities above $5 \mathrm{~ms}^{-1}$. At lower speeds it is not necessary to take this influence into account.

\subsection{Air-steam mixture}

The condensation of the air-steam mixture is a complex process where the change of any parameter (e.g., concentration, cooling water temperature, intensity of diffusion of steam particles in noncondensable air) influences its heat equilibrium. Therefore, each measured state has to be individually balanced. Experiments were carried out for two air concentrations in a mixture with steam $-1.1 \%$ (see Fig. 6) and $2.3 \%$ (see Fig. 7).

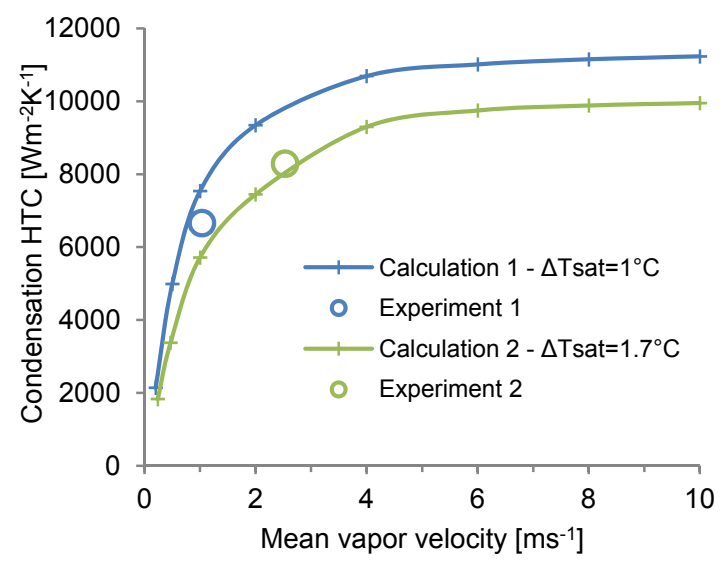

Fig. 6. Effect of flow velocity on the HTC for vapor with $1.1 \%$ of air

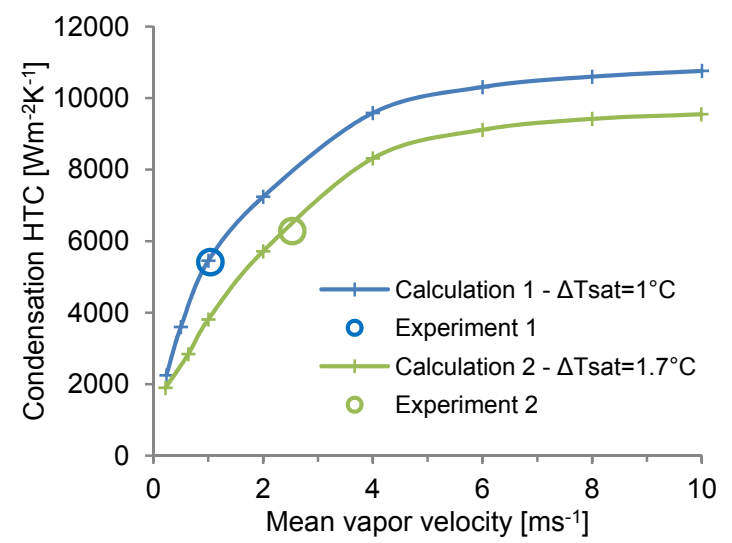

Fig.7. Effect of flow velocity on the HTC for vapor with $2.3 \%$ of air

For each analyzed state, the heat equilibrium of the tested condenser is different. It is evident that the heat transfer affects the thickness of the condensate film and the corresponding temperature difference $\Delta T_{\text {sat }}$ between the condensation and wall side of the film.

Experimental and theoretical results are in good agreement. For air-steam mixture condensation, a significant dependence of the condensation HTC value on the velocity begins at very low velocities.

\section{Discussion}

Comparison of the results for all analyzed cases is shown in Fig. 8. For the range of low velocities, the values of the HTC for pure steam condensation are not sensitive to steam velocity while for air-steam mixture condensation the values of the HTC increase with an increase of the velocity. The presence of the air significantly reduces the value of the HTC for low velocities; on the contrary, the decrease is relatively small at high values of the velocity. However in both cases, the HTC is influenced by the temperature difference $\Delta T_{\text {sat }}$ in the condensate film. The difference 


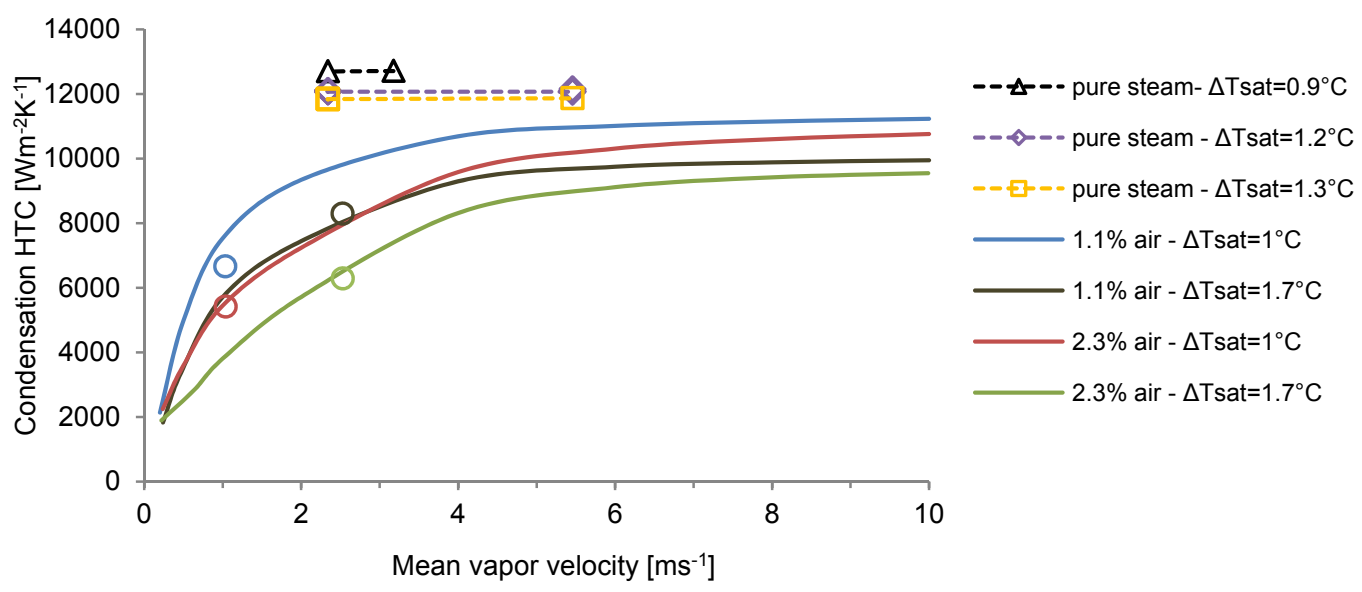

Fig. 8. Total comparison of the effect of gas velocity on the HTC

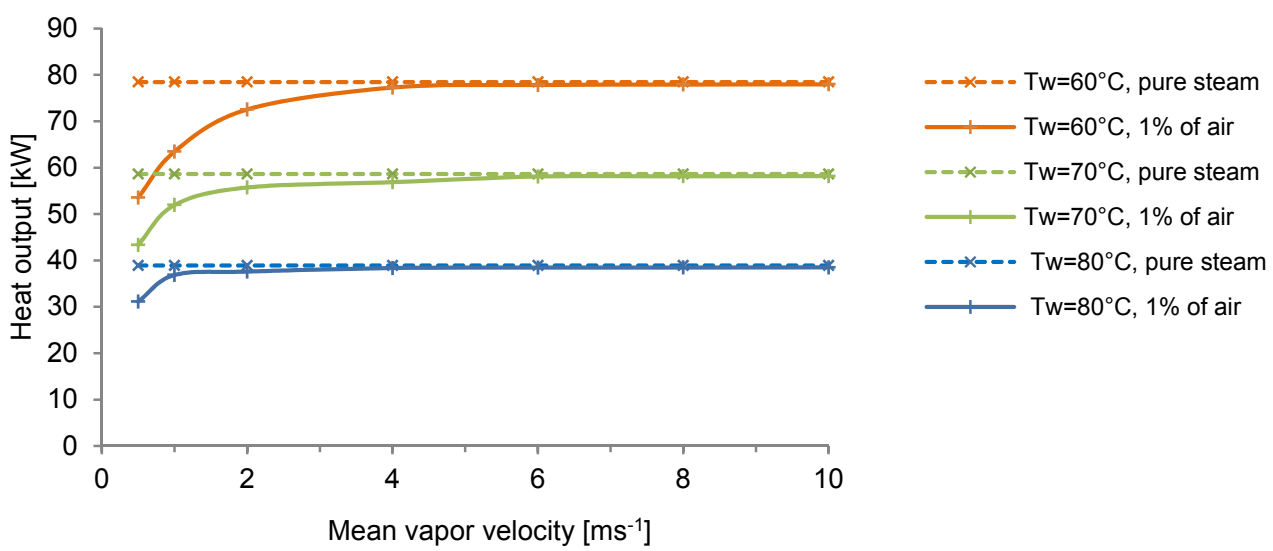

Fig. 9. Comparison of the heat output for various coolling water temperatures

mainly arises from the cooling intensity, respective to the thickness of the condensate film.

The effect of vapor velocity on the heat output of the tested condenser is shown in Fig. 9. For the experimental condenser (Fig. 1), the heat output is theoretically analyzed for various cooling water temperatures $(60,70$ and $80{ }^{\circ} \mathrm{C}$ ) for the case of the condensation of pure steam and $1 \%$ air-steam mixture. The heat output increases with a lower temperature of the cooling water. The presence of the air significantly reduces the value of the heat output as well as the HTC for low velocities; on the contrary, the decrease is relatively small at high velocity values.

\section{Conclusion}

The influence of steam flow velocity on the value of the heat transfer coefficient during the condensation process was theoretically and experimentally investigated.

For the condensation of pure steam, the influence of the flow velocity on the value of the HTC begins to be observed at higher velocity values, conversely, this effect is negligible at low velocity values. On the other hand, when the steam-air mixture is condensed, the influence of flow velocity must always be taken into account. The flow velocity affects the water vapor diffusion process through non-condensing air. The presence of the air significantly reduces the value of the heat transfer coefficient. This drop in the heat transfer coefficient is significant at low velocities; on the contrary, the decrease is relatively small at high velocity values.

This work has been supported by Technology Agency of the Czech Republic, project No. TJ01000192.

\section{Nomenclature}

A heat transfer area $\left(\mathrm{m}^{2}\right)$

c specific heat capacity $\left(\mathrm{Jkg}^{-1} \mathrm{~K}^{-1}\right)$

d diameter $(\mathrm{m})$

D characteristic diameter (m)

$\mathrm{g}$ gravitational acceleration $\left(\mathrm{ms}^{-2}\right)$

$\mathrm{h}$ heat transfer coefficient $\left(\mathrm{Wm}^{-2} \mathrm{~K}^{-1}\right)$

$\mathrm{h}_{\mathrm{fg}}$ latent heat of condensation $\left(\mathrm{kJkg}^{-1}\right)$

$\mathrm{k}$ thermal conductivity $\left(\mathrm{Wm}^{-1} \mathrm{~K}^{-1}\right)$

$\mathrm{L}$ tube length (m)

M mass flow rate $\left(\mathrm{kgs}^{-1}\right)$

$\dot{n} \quad$ molar flux $\left(\mathrm{kmolm}^{-2} \mathrm{~s}^{-1}\right)$

$\mathrm{Nu}$ Nusselt number (-)

Q Rate of heat transfer (W)

$\mathrm{T}$ temperature $(\mathrm{K})$

$\Delta \mathrm{T}_{\log }$ logarithmic mean temperature difference $(\mathrm{K})$

$\mathrm{U}$ overall heat transfer coefficient $\left(\mathrm{Wm}^{-2} \mathrm{~K}^{-1}\right)$

$\mathrm{u}$ velocity $\left(\mathrm{ms}^{-1}\right)$ 
y mole fraction (-)

$\beta$ mass transfer coefficient $\left(\mathrm{ms}^{-1}\right)$

$\mu \quad$ dynamic viscosity (Pas)

$v \quad$ kinematic viscosity $\left(\mathrm{m}^{2} \mathrm{~s}^{-1}\right)$

$\tau \quad$ shear stress $(\mathrm{Pa})$

\begin{tabular}{ll}
\multicolumn{2}{l}{ Subscripts } \\
$\mathrm{f}$ & fluid \\
$\mathrm{g}$ & gas \\
$\mathrm{i}$ & inner \\
$\mathrm{i}$ & interfacial \\
in & inlet \\
$\mathrm{L}$ & liquid \\
o & outer \\
out & outlet \\
ov & overall \\
$\mathrm{S}$ & wall \\
$\mathrm{t}$ & tube \\
$\mathrm{w}$ & water \\
$\infty$ & bulk gas mixture
\end{tabular}

\section{References}

1. G. F. Hewitt, G. L. Shires, T. R. Bott, Process Heat Transfer (Begell House, New York, 2000)

2. J. Havlik, T. Dlouhy, JCEJ 50, $792-798$ (2017)

3. F. P. Incropera et al., Principles of Heat and Mass Transfer (John Whiley, Singapore, 2013).

4. J. Sestak, F. Rieger, Přenos hybnosti tepla a hmoty (CTU, Prague, 2004) (in Czech)

5. H. D. Baehr, K. Stephan. Heat and Mass Transfer (Springer, Berlin, 1998)

6. F. P. Incropera, F. P. et al., Fundamentals of heat and mass transfer (J. Wiley, Hoboken, 2007)

7. T. Kageyama, P. F. Peterson, V. E. Schrock. Nuclear Engineering and Design 141, 289-302 (1993)

8. W. M. Rosenhow, J. H. Webber, A. T. Ling, Trans. ASME 78, 1637-1643 (1956)

9. F. Blangetti, R. Krebs, E. U. Schunder, Chemical Engineering Fundamnetals 1, 20-63 (1982)

10. J. Havlik, T. Dlouhy, EPJ web of conferences 114, 02037 (2016)

11. J. Havlik, T. Dlouhy, EPJ web of conferences 143, 02035 (2017)

12. J. Havlik, T. Dlouhy, Engineering Mechanics 2014, 216-219 (2014)

13. J. Opatril, J. Havlik, O. Bartos, T. Dlouhy, Acta Polytechnica 56, 367-372 (2016)

14. J. Fernández-Seara, F. J. Uhía, J. Sieres, A. Campo, Applied Thermal Engineering 27, 2745 (2007) 